\title{
Please Remember Me: Unintended Consequences Affecting Children of the Incarcerated
}

\author{
Amy Kyle Cook ${ }^{*}, 1$, Robyn L. Diehl ${ }^{2}$ and Gabrielle Brost ${ }^{2}$ \\ ${ }^{I}$ Virginia State University, 1 Hayden Drive, Colson Hall, 200B, Petersburg, VA 23806, USA \\ ${ }^{2}$ Virginia Commonwealth University, Virginia, USA
}

\begin{abstract}
This article explores the ways in which one local church community responded to the devastating effects of parental incarceration. In their efforts to "reverse the jail trail", New Canaan International Church in Richmond, Virginia established a non-profit agency, New Jubilee to promote resilience in children and families from "at risk environments." Initiatives include a partnership with the Virginia Department of Corrections to offer video visitation to inmates and families. In addition, a mentor program is available for children between the ages of 4-18 who have a parent incarcerated in a state or federal institution.
\end{abstract}

Keywords: Parental incarceration, children of the incarcerated, at-risk children, at risk families, incarcerated parent.

The public is often misinformed about the nature and extent of crime. Media accounts tend to exacerbate this problem and fuel the public's already misinformed opinions, while politicians capitalize on the public's frequent demands that "something be done about crime." Unfortunately, this "get tough" approach, primarily begun in the 1980's, appears to have produced unintended consequences for the children of the incarcerated in an effort to satisfy the public's demand for safer communities. Upon examination of the exploding prison population, it certainly seems that something has indeed been done - offenders have been increasingly sentenced to prison.

According to the Sentencing Project, a national organization which promotes reform in sentencing, there has been a 500 percent increase in the number of prison sentences over the past thirty years. Meanwhile, interestingly enough, criminologists claim that crime at its lowest point in thirty years [1]. After providing a brief review of the impact that incarceration has on children, our primary focus is to highlight the needs, resilience and coping mechanisms of these children. We provide illustrative examples of two community-based programs where the Virginia Department of Corrections and a local church in Richmond, Virginia serve the community by responding to families of the incarcerated.

In general, governmental policies produce unintended consequences, both positive and negative. In his paper published in 1936 titled "The Unintended Consequences of Purposive Social Action," the prominent sociologist, Robert $\mathrm{K}$. Merton, analyzed unintended consequences, positing that they are unanticipated outcomes of social action. Merton (1936) popularizes the phrase "unintended consequences" and further describes a variety of sources for them, such as ignorance, error, immediate interest, basic values, and self-

*Address correspondence to this author at the Virginia State University, 1 Hayden Drive, Colson Hall, 200B, Petersburg, VA 23806, USA; Tel: 804827-3514; E-mail: cookak@vcu.edu defeating prophecy, which explain the unexpected nature of the consequences [2]. From a strict public safety perspective, it makes sense intuitively that widening the net and incarcerating more offenders are accomplished in order to promote safe streets and offender accountability. However, there are serious unintended consequences that have resulted from the practice of mass incarceration. While it is outside of the scope of this piece to unravel the policy-making process with respect to the unintended consequences of mass incarceration, specifically relating to children and families, we refer the reader to the sources authored by Merton (1936) that may offer viable explanations.

\section{PARENTAL INCARCERATION AND CHILDREN AT RISK}

As of mid-year 2007 , over 800,000 of the 1.5 million prisoners in the United States were parents of children under the age of 18 [3]. Additionally, 52 percent of state inmates and 63 percent of federal inmates were estimated as having 1.7 million children among them [3]. This is only part of the story - this rate of incarceration also represents a 79 percent increase in the number of parents sentenced to state and federal prisons [3]. More specifically, between 1991 and 2007, the number of mothers sentenced to prison more than doubled, reflecting a growth rate of 122 percent versus that of fathers, which was up 76 percent [3]. Furthermore, Glaze \& Maruschak (2008) reported that 77 percent of mothers and 26 percent of fathers provided most of the daily care for their children prior to incarceration [3].

Beyond absenteeism, parental incarceration presents children with a unique set of circumstances that may compound other risk factors present in the child's life. Children with incarcerated parents are more likely to experience significant psychosocial maladjustment [4], which may contribute to delinquency and future criminal behavior [5]. Dallaire and Wilson (2009) found that children who witnessed their parent's arrest, criminal activity, and sentencing were more likely to display markers for 
psychosocial maladjustment than other children who did not witness these activities [4].

The majority of children with incarcerated parents come from poverty-stricken minority households, with AfricanAmerican children accounting for over 50 percent of all children with incarcerated parents [6]. As a result of this situation, African-American children with incarcerated parents may experience a higher level of cumulative risk than children without incarcerated parents [6]. Children with incarcerated parents are also more likely than other children to come from a home where there are multiple family problems [7]. The disruption caused by parental incarceration can exacerbate problems such as poor communication and heightened dysfunction in the family and may increase the child's risk for developing behavioral and emotional problems [8]. Further disruption such as changing schools, moving, and living with other caregivers (such as grandparents) can also disrupt the stability in a child's life and contribute to poor academic performance, poor peer relationships, and insecurity $[9,10]$

\section{RESILIENCE: STRENGTH IN THE FACE OF ADVERSITY}

It is clear that the children of incarcerated parents face a myriad of obstacles to healthy development, but it is important to note that not all such children experience negative outcomes. Philips \& Harm (1997) support this assertion that a group of at-risk youth responded with resilience to the "enduring trauma" of parental incarceration [11] and avoid the difficulties associated with it. Resilience refers to success and positive outcomes in the face of adversity [12]. Most often, resilience has been conceptualized as an internal or inherent trait which allows children to cope with stress in a functional way [12]. or as a process in which children are able to develop a level of competency to cope with stress while facing adverse conditions $[12,13]$. An alternative definition describes the ability to recover from stressors or difficult life situations [6]. It is beyond the scope of this paper to discuss the pros and cons of each conceptualization. Yet, it is important to note that although resilience can be thought of in many different ways, the shared meaning involves each individual's ability to succeed, despite adversity. Children with resilience are more likely to succeed despite parental incarceration and other aversive life stressors. Children with incarcerated parents are faced with many difficult life situations that increase their risk for negative outcomes. Interestingly, the same factors that put children at risk may also aid in their resiliency in the face of parental incarceration. For example, many children struggle with separation from the parent and transfer to another caregiver; however, this transition may be beneficial for the child. In further examining the impact of incarceration on delinquency, Aaron \& Dallaire (2010) suggest that the influence of family conflict and family victimization better predicts delinquency than does parental incarceration [14]. Children with incarcerated parents are more likely to come from homes with a disengaged parent, a home where substance abuse is present, and/or a home where criminal activity is present [15].
Removal of the parent and transfer to an engaged caregiver may help children develop healthy coping skills, receive much-needed support, and encourage healthy development [16]. Many children also develop healthy outlets for their emotional stress during parental incarceration through activities such as sports, art, and other community involvement [16]. These positive outlets help buffer children from negative outcomes associated with parental incarceration, promote confidence, and encourage new friendships with a supportive peer group [16]. A supportive network of peers and caregivers, along with an outlet for frustration and stress, appear to promote resilience in children of incarcerated parents and protect them from negative developmental outcomes.

\section{HELPING OUR CHILDREN: TURNING RISK INTO RESILIENCE}

Encouraging resilience in children with incarcerated parents can be difficult, but necessary to buffer at-risk youth from the negative effects of parental incarceration. This process begins within the community and with family environment. There are multiple mentoring programs and kinship care support groups that assist children and caregivers dealing with parental incarceration. Several mentoring programs are available to youth with incarcerated parents, including programs through the Virginia Mentoring Partnership, which has developed a comprehensive network of mentoring opportunities in Virginia. For example, programs such as Mentoring Children of Prisoners (MCP) and Mentoring Children of Incarcerated Parents match children with an adult mentor (for an example, see Children without Fathers Organization) [17] to promote positive development and provide a positive role model. These are just a few examples of the many programs and non-profit organizations that offer support and guidance to children of incarcerated parents.

There are also programs that offer support to families and new caregivers of children with incarcerated parents, such as Kinship Care support groups. In Virginia, there are several free Kinship Care support groups that focus on grandparents and other family members who are caring for children that have parents who are unable to care for them. These support groups offer a valuable opportunity for caregivers to share experiences, create a support network, and discuss solutions to problems associated with kinship care. These mentoring and support programs should be made known to the offender's family and the child's caregiver, since they are an important resource that can foster resilience [18].

The criminal justice system, especially the Department of Corrections, also plays a crucial role in the process of turning risk into resilience. Programs sponsored through this department regarding children of offenders, family preservation, and parenting are important to examine, as these policies have resounding ramifications for families of incarcerated offenders. Maintaining contact between the incarcerated parent and the child has been found to foster better outcomes for children [19] and reduce recidivism rates for parents [20]. Formal policies encouraging visitation and parenting programs have only begun to gain popularity within the past two decades [19]. 
While the Department of Corrections encourages visitation by family members, for many reasons it is often difficult for children to visit their parents. Face-to-face visits can be problematic due to the distance between the family's home and the location of the prison, the expense of traveling, which can be a burden, and occasional conflicts for caretakers who are the gatekeepers to parental visitations $[16,19,21]$. The relationship between the caretaker and the incarcerated parent is one of the most important factors affecting the frequency of contact between the child and parent [22]. While Hoffman et al. (2010) found that corrections departments made efforts to assign offenders to facilities close to their families; this was not always the case for female prisoners, due to the fewer number of female facilities [19]. Furthermore, Department of Corrections policies are often difficult for children to adjust to because they require long waiting periods, short visitation periods, strict rules, and limited personal contact [23].

Corrections departments often offer guides to families to help explain visitation procedures. The Virginia Department of Corrections offers a comprehensive "Family and Visitor Guide" that describes the criminal justice process, visitation rules, and various other policies to families of offenders. This guide also discusses programs and services offered to offenders. One noteworthy program is the Female Offender Program, available at Virginia women's facilities. This program includes parenting classes and helps women improve relationships with their children during and after incarceration [24]. Recently, the Virginia Department of Corrections expanded their Video Visitation Program that allows families to video chat with incarcerated offenders without spending the time and money required to travel [25]. Implementing programs such as video visitation are extremely beneficial for children with incarcerated parents, since they may receive the benefits of parental visitation without the difficulties associated with traditional face-toface visits. The development and implementation of more family-friendly and child-friendly policies, such as video visitation, are critical to helping children maintain contact with their incarcerated parents. This contact may strengthen the child's resilience to negative developmental outcomes and is a cost-efficient way to turn risk into resilience.

\section{FINDING COMMON GROUND: EXTENDING A HELPING HAND}

Government agencies are not bearing the responsibility for video visitation programs alone. The old African proverb, "It takes a village to raise a child", is still apropos today. Nearly ten years ago, in deciding "how to reverse the jail trail" [26] the New Canaan International Church in Richmond, Virginia established a non-profit agency, the New Jubilee Educational and Family Life Center, in order to reach "at-risk" families without the stigma of using the term "at-risk" in a pejorative sense. New Jubilee's goal was to work with families in "at risk environments" in order to provide them with the tools they needed to strengthen relationships within their families and live pro-social lives. In their quest to determine how to best help families, Owen Cardwell and others travelled the country to observe existing programs that served children of incarcerated parents. Inspired by the work they witnessed, Owen Cardwell began connecting programs with one another so that they were knowledgeable as to other existing services and to avoid duplication of services, given limited personnel and funding.

In continuing with the mission of how to reverse the jail trail, New Jubilee fortuitously acquired equipment that would make video visitation possible. After approaching the Virginia Department of Corrections, a series of planning sessions took place, and in April 2006, the Virginia Department of Corrections began its first video visitation program at Wallens Ridge State Prison. Through video conferencing, inmates meeting certain behavioral criteria have the opportunity to visit face-to-face for 50 minutes with their loved ones. Due to its popularity, the program was expanded. Currently, there are three churches in Richmond, Alexandria, and Norfolk, Virginia providing video services to five state prisons. To date, New Jubilee has provided video visitation services to approximately 2,200 family members and over 650 inmates [26].

New Jubilee has identified one area in particular that is in need of improvement - marketing to inmates. Under the current system, all video visits are family-generated rather than inmate-generated. This is likely due to the fact that inmates are often unaware of the video visitation program. The hope is that moving towards an inmate-generated system will increase video visitation for those for whom face-to-face contacts are not feasible. Video visitations were not implemented to replace face-to-face contact, but rather to reach those prisoners that were not receiving any visits at all. Increased awareness efforts within the prisons will likely include flyers, posters, DVDs, published information given to inmates during admission to the facility, and information sent to families of the incarcerated. New Jubilee is strongly rooted in the idea of community and asserts that a coordinated effort is the key to success.

In addition to providing video visitation services, New Jubilee was recently awarded a three-year grant from the Department of Health and Human Services' Administration of Children, Youth, and Families to provide mentoring services for three zip codes in Richmond, Virginia. The Each One, Reach One mentoring program is the only program in the City of Richmond to focus on children of incarcerated parent's, unlike other Statewide programs like the Big Brothers/Big Sisters programs, that serve a broader population of children and maintain a different overall purpose. Children between the ages of 4-18 whose parent is incarcerated in a state or federal institution may qualify for a one-to-one mentor. Although the Each One, Reach One mentoring program is in its infancy, over the course of the next three years, the grant will provide a total of 180 children with mentors. Mentors will focus on building lasting relationships, enhancing self-esteem, and promoting positive development with these youth. Researchers have found that youth who receive frequent visits with mentors for at least six months have revealed fewer internalizing and externalizing symptoms [27].

While empirical evidence is not currently available as to the effectiveness of the programs offered by New Jubilee, their commitment and ongoing efforts to improve the lives of families in their community are impressive. As for the mentoring program, New Jubilee is receiving federal funding, so outcome data are expected over time. Although turning risk into resilience presents challenges, researchers 
have shown that informed policies and practices can make a difference. From the point of arrest, police departments must be educated as to how children respond to witnessing their parent's arrest and develop guidelines to protect children from adverse conditions when their parents are arrested [28]. In addition, best practices should be a collaborative effort between all agencies and parties coming into contact with children of incarcerated parents, including police departments, child welfare agencies, schools, communitybased partnerships such as New Jubilee, courts, correctional facilities, treatment programs for substance abuse and mental health, and the families themselves. It is imperative that correctional facilities take advantage of the captive audience they have and educate, support, train, shape, and/or reintroduce, if necessary, the importance of parenting. Collaborative efforts, formal partnerships, and childrenfriendly policies are more likely to increase resilience levels in children rather than "business as usual" policies that have done little to improve outcomes for children with incarcerated parents.

Since it does not appear that incarceration numbers are likely to decrease any time soon, community programs, service providers, government agencies, and other interested partnerships need to share the responsibility for strengthening families and children in "at risk" environments. After all, children and families do not exist in a vacuum. Although it has been shown that children and families of an incarcerated individual present a number of significant challenges, proper assessment and provision of effective services can counteract many obstacles. The needs of these children vary, and should be considered in the context of the circumstances surrounding each unique family situation. Successful implementation of the recommendations shared in this paper could readily lead to replacing the unintended negative consequences with truly intended consequences of the best kind.

\section{ACKNOWLEDGEMENT}

None declared.

\section{CONFLICT OF INTEREST}

None declared.

\section{REFERENCES}

[1] Walker S. Sense and non-sense about crime, drugs, and communities. $7^{\text {th }}$ ed. Belmont, CA: Wadsworth Cengage Learning 2011.

[2] Merton RK. The unintended consequences of purposive social action: Am Sociol Rev 1936; 1(6): 894-904.

[3] US Department of Justice; Bureau of Justice Statistics. Parents in prison and their minor children. (NCJ Publication No. NCJ222984). Rockville, MD: Glaze EL, Maruschak, LM, 2008.

[4] Dallaire DH, Wilson LC. The relation of exposure to parental criminal activity, arrest, and sentencing to children's maladjustment. J Child Fam Stud 2010; 19: 404-18.
[5] Dannerback, AM. Differences in parenting attributes, experiences and behaviors of delinquent youth with and without a history of parental incarceration. Youth Violence Juvenile Just 2005; 3: 199213.

[6] Miller KM. Risk and resilience among African American children of incarcerated parents. J Hum Behav Soc Environ 2007; 15(2/3): 25-37.

[7] Myers BJ, Smarsh TM, Amlund-Hagen K, Kennon S. Children of incarcerated mothers. J Child Fam Stud 1999; 8:11-25.

[8] Amlund-Hagen K, Myers BJ, Mackintosh VH. Hope, social support, and behavioral problems in at-risk children. Am J Orthopsychiatry 2005; 75(2): 211-9.

[9] Green M, Scholes M. Education for what? Attachment, culture, and society. In: Green M, Scholes M, Eds. Attachment and human survival, Karnac 2004; pp.37-51.

[10] Poehlmann J. Representations of attachment relationships in children of incarcerated mothers. Child Dev 2005; 76: 679-96.

[11] Phillips S, Harm N. Women prisoners: A contextual framework. Women Ther 1997; 20: 1-9.

[12] Kirby LD, Fraser MW. Risk and resilience in childhood. In: Kirby LD, Fraser MW, Eds. Risk and resilience in childhood: An ecological perspective, NASW press 1997; pp.10-33

[13] Richardson GE. The metatheory of resilience and resiliency. J Clin Psychol 2002; (58) 2: 307-21.

[14] Aaron L, Dallaire DH. Parental incarceration and multiple risk experiences: Effects on family dynamics and children's delinquency. J Youth Adolescence 2010; 39: 1471-84.

[15] Lotze GM, Ravindran N, Myers BJ. Moral emotions, emotion selfregulation, callous-unemotional traits, and problem behavior in children of incarcerated mothers. J Child Fam Stud 19(6): 702-13.

[16] Nesmith A, Ruhland E. Children of incarcerated parents: Challenges and resiliency, in their own words. Child Youth Serv Rev 2008; 30: 1119-30.

[17] Seton Youth Shelters. Mentoring. [Online]. 2011 Jan 25 [cited 2010]. Available from: http://www.setonyouthshelters.org/progra ms/mentoring.html

[18] Virginia Department of Social Services. Kinship Care. [Online] 2011 Jan 25 [cited 2008]. Available from: http://www.dss.virgi nia.gov/family/fc/kinship.cgi

[19] Hoffman HC, Byrd AL, Kightlinger AM. Prison programs and services for incarcerated parents and their underage children: Results from a national survey of correctional facilities. Prison J 2010; 90(4): 397-416.

[20] Casey-Acevedo, K, Bakken, T. Visiting women in prison: Who visits and who cares? J Offender Rehabil 2002; 34(3): 67-83.

[21] Davies, E, Brazell, D, Vigne, N, Shollenberger. Understanding the experiences and needs of children of incarcerated parents. Urban Institute. Justice Policy Center 2008.

[22] Christian, J. Riding the bus: Barriers to prison visitation and family management strategies. J Contem Criminal Just 2005; 21: 31-48.

[23] Slavin, P. Children with parents behind bards: They serve a sentence of their own. Children's Voice Child Welfare League of America 2000; 9(5).

[24] Virginia Department of Corrections. Family and visitor information guide [Online]. 2011 Jan 25 [cited 2004]. Available from: http:// www.vadoc.state.va.us/resources/family-guide.pdf

[25] Virginia Department of Corrections. Video Visitation Program. [Online]. 2011 Jan 25 [cited 2010]. Available from: http://www. vadoc.virginia.gov/offenders/prison-life/videoVisitation.shtm

[26] Owen Cardwell DTH. Personal communication. Richmond, VA. January 20, 2011.

[27] Shlafer RJ, Poehlmann J, Coffino B, Hanneman A. Mentoring children with incarcerated parents: Implications for research, practice, and policy. Fam Relat 2009; 58: 507-19.

[28] American Bar Association. Responses to children during a parent's arrest. Child Law Pract 2010; 29(2): 30-2. 